\title{
Health Care Effect of Disease-Modifying Antirheumatic Drug Use on Patients with Rheumatoid Arthritis
}

\author{
Natalie N. Boytsov, PhD; Ritupurna Bhattacharya, PhD; Kim Saverno, PhD, RPh; Laurin Dixon, PharmD; \\ Paul L. Abbott, MBA; Xiang Zhang, PhD; Carol L. Gaich, PharmD, RPh; and Radhika Nair, PhD
}

\begin{abstract}
BACKGROUND: Disease-modifying antirheumatic drugs (DMARDs) are recommended as the standard of care for patients with rheumatoid arthritis (RA) due to their ability to reduce pain and disability; however, DMARD use is low in some subgroups of the RA population.
\end{abstract}

OBJECTIVE: To identify characteristics associated with DMARD use in the overall cohort of patients with RA and newly diagnosed RA patients.

METHODS: This retrospective observational study used claims from a large national health plan. Use of DMARDs was measured according to the Healthcare Effectiveness Data and Information Set (HEDIS) as the proportion of patients with RA receiving DMARDs. Following HEDIS measure technical specifications, we identified patients aged 18-89 years with continuous enrollment during 2014 (measurement year) with $\geq 2$ claims for RA outpatient visits and/or discharges on different dates between January and November 2014. Additionally, we identified a subset of patients newly diagnosed with RA in 2014 based on absence of any claims for RA or DMARDs in 2013. Descriptive analyses and bivariate associations were used to compare demographic and clinical characteristics of patients with RA with or without DMARD use in 2014. Health care resource utilization (HCRU) and costs were compared in 2014 for patients enrolled in Medicare Advantage Prescription Drug (MAPD) plans during both 2014 and 2015. Regression models were used to evaluate patient and provider characteristics associated with DMARD use in 2014 and the effect on HCRU and costs.

RESULTS: Among the 33,880 patients identified with RA in 2014, most patients received a DMARD $(75.2 \%) ; 29.4 \%$ of patients newly diagnosed with RA had been treated with DMARDs in 2014. Patients with DMARD use, on average, were younger (aged 67 years \pm 10.7 vs. 69 years \pm 10.7 ) and healthier (Deyo-Charlson Comorbidity Index [DCCI] $2.4 \pm 1.9$ vs. $2.6 \pm 2.1$ ) and included a greater proportion of women $(75.9 \%$ vs. $71.0 \%)$ than those with no DMARD use $(P<0.0001)$. Use of DMARDs $(P<0.0001)$ was associated with $14.5 \%$ fewer hospitalizations and $18.0 \%$ fewer emergency department visits. Although total costs increased by $15.0 \%$ with use of DMARDs, when the cost of DMARDs was excluded, the total cost decreased by $13.7 \%(P<0.0001)$. Female gender $(32.2 \%)$, higher claims-based index for RA severity score (47.0\%), higher RxRisk-V score $(26.7 \%)$, visit to a rheumatologist $(34.3 \%)$, and use of glucocorticoids $(17.7 \%)$ increased the odds of DMARD use $(P<0.0001)$. Use of certain classes of medication, such as nonsteroidal anti-inflammatory drugs $(12.3 \%)$, opioids (19.5\%), antidepressants $(20.0 \%)$, muscle relaxants $(12.5 \%)$, and anticonvulsants $(15.5 \%)$, were associated with lower use of DMARDs $(P<0.0001)$.

CONCLUSIONS: We found significant differences in demographic and clinical characteristics between patients with and without DMARD use, which can potentially inform treatment decisions regarding DMARD use as deemed necessary by the provider. Future research should investigate the reasons for lack of treatment.

J Manag Care Spec Pharm. 2019;25(8):879-87

Copyright $\odot 2019$, Academy of Managed Care Pharmacy. All rights reserved.

\section{What is already known about this subject}

The proportion of patients with rheumatoid arthritis (RA) receiving treatment with disease-modifying antirheumatic drugs (DMARDs) has been increasing over the years.

The Healthcare Effectiveness Data and Information Set national average for 2014 DMARD treatment rate for Medicare Advantage Prescription Drug plans was $76.7 \%$ for health maintenance organization plans and $80.5 \%$ for preferred provider organization plans. Use of DMARDs is higher among patients under the care of a rheumatologist.

\section{What this study adds}

The majority of patients in this study received a DMARD (75.2\%) during the measurement year, but only $29.4 \%$ of patients newly diagnosed with RA were treated with DMARDs in 2014.

Use of medications, such as nonsteroidal anti-inflammatory drugs and opioids, were associated with lack of DMARD use, which may suggest that these pain medications are being used for symptomatic management of RA in place of DMARD treatment. Use of DMARDs was associated with fewer hospitalizations, fewer emergency department visits, and lower total health care costs excluding DMARDs, compared with those without DMARD use.

$\mathrm{R}$ heumatoid arthritis (RA) is an autoimmune and chronic inflammatory disease in which the immune system attacks healthy joints. RA primarily manifests itself in joint damage through synovial inflammation but has been shown to affect respiratory, cardiac, neurologic, and hematologic systems too. ${ }^{1}$ According to a recently published study, the overall age-adjusted prevalence of RA in the United States ranges from $0.53 \%$ to $0.55 \%$, affecting an estimated $1.28-1.36$ million adults. ${ }^{2,3}$

Disease-modifying antirheumatic drugs (DMARDs) have been recommended as the standard of care for patients with established and early RA over the past several decades because of their effect on pain reduction and disability. ${ }^{4-9}$ DMARDs have been shown to delay progression of RA, including slowing the development and progression of joint damage. A delay greater than 12 weeks in referral to treat a patient with DMARDs has been linked to increased joint destruction and reduction of opportunity to achieve DMARD-free remission; however, 
DMARDs do not halt disease progression in most patients. ${ }^{10,11}$ Despite evidence supporting the effectiveness of DMARDs in treating RA, previous real-world studies using health care claims databases have reported that a large proportion of patients (45\%-60\%) are not treated with DMARDs after RA diagnosis. ${ }^{12-18}$

To address the DMARD treatment gap in patients with RA, the National Committee for Quality Assurance (NCQA) issued an update to the Healthcare Effectiveness Data and Information Set (HEDIS) in 2005 to assess the receipt of DMARDs among patients with RA by the disease-modifying antirheumatic drug therapy for rheumatoid arthritis (ART) measure. ${ }^{19}$ The ART measure is defined as the "percentage of members who were diagnosed with RA during the measurement year (denominator), and who were dispensed at least 1 ambulatory prescription for a conventional or biologic disease-modifying antirheumatic drug (DMARD) (numerator)." Managed care organizations offering Medicare plans are required to report performance on this measure, along with other HEDIS measures.

The ART HEDIS measure is also part of the Centers for Medicare \& Medicaid Services' (CMS) star rating measure for Medicare Advantage Prescription Drug (MAPD) plans. CMS publishes the Part $C$ and $D$ star ratings each year to measure quality of MAPD plans and can include a variety of quality measures related to clinical care, operational, and medication use. MAPD plans are awarded star scores at the individual measure level and the overall performance level on a scale of 1-5. A health plan's ability to deliver a high level of service not only affects its reputation in a competitive industry, but it also determines the level of performance incentives the plan will receive from CMS. Plans are deemed as high performance when at least an overall 4-star rating level is achieved. For MAPD plans, the average 2014 DMARD treatment rate for health maintenance organization (HMO) plans was 76.7\%, while for preferred provider organization (PPO) plans it was $80.5 \%,{ }^{20}$ which fell below the 4 -star rating threshold (82\%) for that year. The national average star rating for DMARD treatment rate was 3.7 in 2014 and 3.5 in 2015. ${ }^{21}$

The goal of this study was to identify modifiable and nonmodifiable characteristics associated with DMARD use per the ART measure among patients with RA. Additionally, we evaluated the effect of DMARD use on health care resource utilization (HCRU) and costs during 2015 (the year following the measurement year). We also conducted a separate assessment of DMARD use among patients newly diagnosed with RA.

\section{Methods}

This was a retrospective observational study utilizing administrative claims data from a large national health plan. The claims data included medical and pharmacy claims for individuals enrolled in an MAPD plan or a commercial plan with medical and pharmacy benefits. All study definitions and patient selection criteria followed an institutional review board approved study protocol and statistical analysis plan.

The primary measure of this study was the proportion of patients with at least 1 prescription claim for a DMARD among the patients identified with RA during the measurement year of 2014. The DMARDs were further classified into conventional synthetic (csDMARDs) and biologic DMARDs (bDMARDs). The bDMARD category included tumor necrosis factor inhibitors (TNFi), non-TNFi biologics, and Janus kinase inhibitors (JAKi).

\section{Patient Selection}

This study followed the 2014 HEDIS criteria to identify patients for the analysis. ${ }^{19}$ The year 2014 was set as the measurement year per HEDIS definitions. Individuals aged 18-89 years as of December 31, 2014, diagnosed with RA on or between January 1, 2014, and November 30, 2014, were identified. Diagnosis of RA was defined as having at least 2 claims, either for outpatient visit and/or a nonacute inpatient visit, with RA diagnosis (714.0-714.2, 714.81) on 2 separate days during the measurement year. Patients were required to be continuously enrolled (allowing for a gap up to 45 days) in plans with medical and pharmacy benefits during the measurement year of 2014. Pregnant women and patients with a human immunodeficiency virus (HIV) diagnosis were excluded per HEDIS requirements.

Among patients who fulfilled the study criteria, we further identified 2 patient subgroups for additional analyses. One subgroup included patients newly diagnosed with RA. They were continuously enrolled for 1 year before (2013) the start of the measurement year (2014) and neither had a diagnosis of RA nor used a DMARD during the premeasurement year. Another subgroup included all patients who were enrolled in MAPD plans during the measurement year (2014) and the following year (2015). This subgroup was defined for evaluation of effect of DMARD use on HCRU and costs. HCRU and costs are usually different for those enrolled in commercial health insurance compared with those enrolled in MAPD plans (majority are aged 65 years and older). ${ }^{22-24}$ Additionally, because the study population was predominantly enrolled in MAPD plans ( 90\%), the HCRU and costs were reported only for those enrolled in MAPD plans during the measurement year and follow-up year.

\section{Patient Characteristics}

We identified patient demographic characteristics as of December 31, 2014, including age; gender; race; type of insurance (MAPD or commercial); geographic region (Northeast, Midwest, South, and West); and urban/rural residency. The clinical characteristics identified during the measurement year included biomarker tests, comorbidity indices, and medication use. The specific biomarker tests identified were 
rheumatoid factor, cyclic citrullinated peptide antibody, C-reactive protein, and erythrocyte sedimentation rate tests. $\mathrm{DCCI}^{25-27}$ and RxRisk-V ${ }^{28}$ scores were calculated for each patient. To understand the potential role of severity of RA in DMARD use, we used a claims-based index for RA severity (CIRAS) developed by Ting et al. (2008). ${ }^{29}$ Use of the following medication classes was assessed: nonsteroidal anti-inflammatory drugs (NSAIDs), opioids, glucocorticoids, muscle relaxants, antidepressants, and anticonvulsants. Other patient characteristics included time of first claim with RA diagnosis and time between first 2 claims with RA diagnosis during the measurement year.

HCRU included hospitalizations, outpatient, emergency department (ED) and rheumatologist visits, use of durable medical equipment, physical therapy, and skilled nursing facility stay. Total all-cause health care costs (medical and pharmacy) along with total medical and total pharmacy costs were reported for these patients and included both the patient and plan's portion. Total costs excluding DMARD-related costs from medical and pharmacy costs were also reported to demonstrate the cost offset related to DMARD use.

\section{Provider Characteristics}

For the purposes of this study, we developed an algorithm to identify the provider associated with care for the patient with RA. Each patient in the study was assigned a principal provider. A rheumatologist was assigned as the principal provider to all patients with at least 1 claim for a rheumatologist visit. For patients with no claim for a rheumatologist visit, the principal provider, irrespective of specialty, associated with first observed claim with RA diagnosis and prescription for DMARD was assigned. If no provider associated with the DMARD prescription and claim with diagnosis for RA could be identified, the provider associated with the claim with RA diagnosis (given priority to a primary diagnosis position on the claim) was assigned as the principal provider. If no provider could be assigned, then the value was set to missing.

Provider-related characteristics included provider specialty; type of practice (facility, group, or solo); provider type (medical doctor [MD] vs. non-MD); provider location (region); and number of providers managing care of the patient (number of unique providers prescribing medications and diagnosing conditions). Non-MD providers included nurses, physician assistants, doctor of osteopathy, and others.

\section{Statistical Analyses}

Descriptive analyses and bivariate associations were used to compare demographic and clinical characteristics of patients with RA with and without DMARD use during the measurement year. Categorical variables were compared using chisquare tests/Fisher's exact test and continuous variables were compared using 2-sample t-tests/Wilcoxon rank sum test as appropriate. We compared HCRU and costs by DMARD use in
2014 for patients continuously enrolled in MAPD plans during both the measurement year and the follow-up year. As part of a sensitivity analysis, the HCRU and costs were evaluated for patients continuously enrolled during both the measurement year and follow-up year and who had use of DMARDs during both years.

Multivariable logistic regression was used to evaluate patient and provider characteristics associated with DMARD use among patients with RA. Generalized linear models (GLM) with Poisson distribution and log-link functions were used to evaluate the effect of DMARD use on selected HCRU variables (hospitalizations, ED visits, and outpatient visits) for patients enrolled in MAPD plans. Since cost variables are often skewed due to presence of individuals with no (zero) costs, a 2-part model was used to address the number of missing cost variable values. ${ }^{30}$

In this model, first a logistic regression was used to assess the probability of incurring a nonzero cost associated with DMARD use among all patients enrolled in MAPD plans, and then GLMs with gamma distribution and log-link functions were used to evaluate the effect of DMARD use on total health care costs (including and excluding DMARDs) during the follow-up year among those who had a nonzero cost. All regression models were adjusted for patient demographics, clinical characteristics, HCRU and costs, and provider characteristics identified for the measurement year.

\section{Results}

After applying the study inclusion and exclusion criteria, we identified 33,880 patients aged between 18 and 89 years, with $\geq 2$ claims with diagnostic codes for RA in 2014. In the overall population with RA and enrolled in 2014, a majority of these patients received a DMARD (75.2\%) during the measurement year (Figure 1).

In the overall population, patients with no DMARD use were slightly older (aged 69 years vs. 67 years, $P<0.0001$ ) compared with those with DMARD use (Table 1). Although there were some differences between those with DMARD use and with no DMARD use, in both groups the majority of the patient population comprised white women (>70\%) living in the South $(\sim 69 \%)$ and enrolled in MAPD plans (> 85\%). A significantly greater proportion of patients with DMARD use underwent biomarker tests, especially C-reactive protein (62.1\% vs. 34.8\%, $P<0.0001)$ and erythrocyte sedimentation rate tests $(69.7 \%$ vs. $43.4 \%, P<0.0001)$ compared with patients with no DMARD use (Table 2).

Among those with DMARD use, the majority of the patients (93.8\%) filled at least 1 prescription for a csDMARD (Table 2). The average and median time between the first and second RA diagnosis during the measurement year was shorter for patients with DMARD use (49.5 days \pm 49.0 ; median 34 days) compared with those with no DMARD use $(64.9 \pm 61.6$; median 44 days; $P<0.0001$ ). 


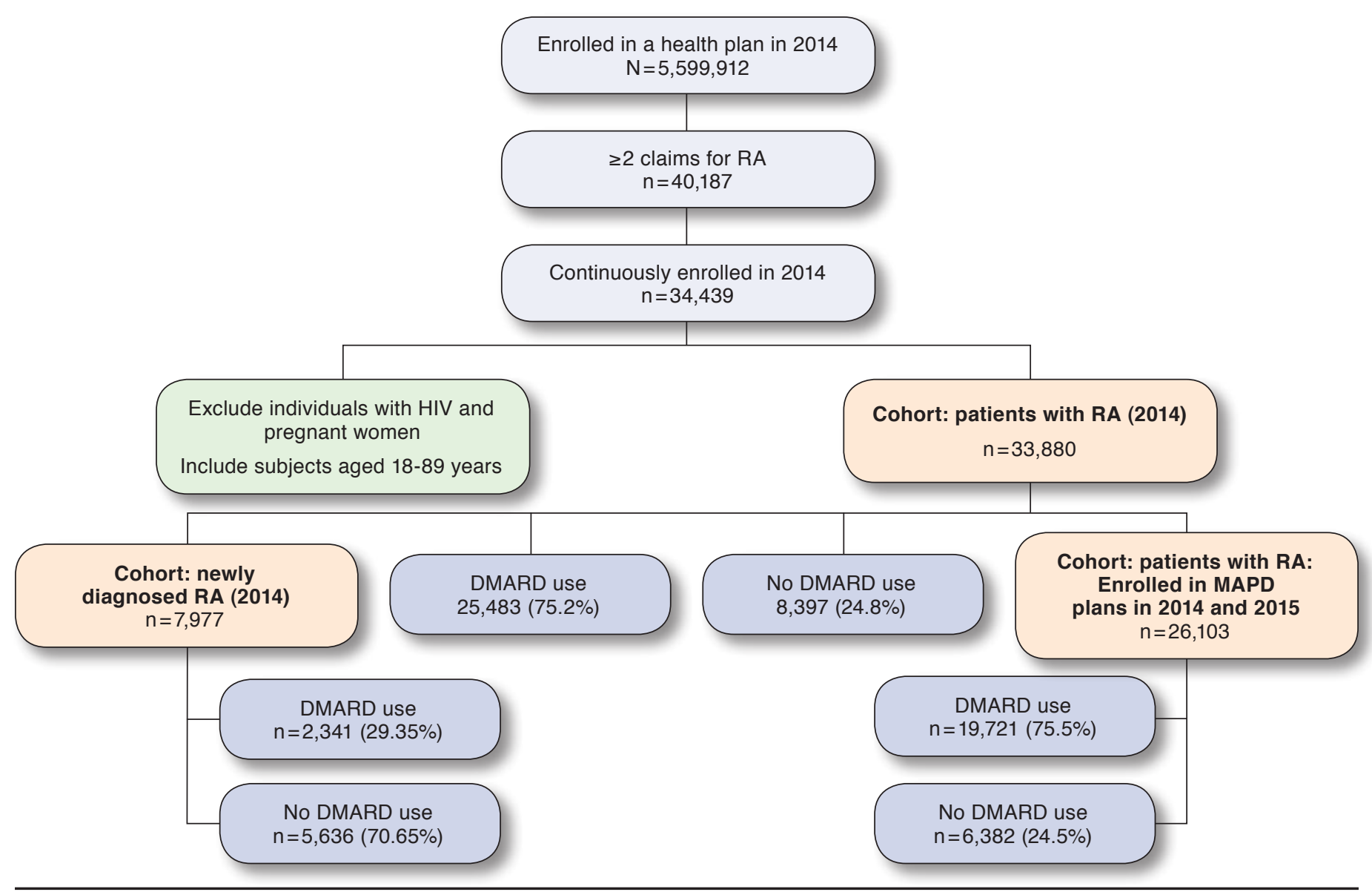

DMARD = disease-modifying antirheumatic drug; HIV=human immunodeficiency virus; MAPD= Medicare Advantage Prescription Drug; RA = rheumatoid arthritis.

The majority of the principal providers were primary care providers for patients with DMARD use (51.7\%) and no DMARD use (59.6\%), followed by rheumatologists (Table 2). However, a greater proportion of patients with DMARD use (27.4\%) visited a rheumatologist compared with patients with no DMARD use (13.2\%). Additionally, a greater proportion of patients with no DMARD use (10.6\%) had non-MD visits than the group with DMARD use (6.1\%).

Table 3 depicts the HCRU and costs for patients with RA with and without use of DMARDs, who were enrolled in MAPD plans during the measurement year and the following year. The demographic and clinical characteristics of this population enrolled in MAPD plans in 2014 and 2015 with RA were similar to that of the overall RA population (results not shown). Patients with DMARD use had similar number of hospitalizations (mean $0.3 \pm 0.7$ vs. $0.4 \pm 0.8$ ) and $\mathrm{ED}$ visits (mean $0.9 \pm 1.9$ vs. $1.1 \pm 2.3$ ), compared with those with no DMARD use during the measurement year. On the other hand, patients with DMARD use had more outpatient visits (mean $21.5 \pm 15.4$ vs. $19.9 \pm 16.1$; median 18.0 vs. $16.0, P<0.0001)$ compared with patients with no DMARD use during the measurement year.

The median total costs (medical plus pharmacy) were higher among patients with DMARD use compared with patients with no DMARD use during the measurement year $(\$ 9,079.40$ vs. $\$ 6,686.70, P<0.0001)$. After excluding DMARD-related treatment costs, the difference in median total costs between patients with and without DMARD use were substantially reduced during the measurement year $(\$ 115.00)$ and the follow-up year (\$590.00). The sensitivity analyses evaluating HCRU and costs among patients with DMARD use in both measurement and follow-up year (results not shown) produced similar results. The descriptive analyses of HCRU show minimal differences in number of ED visits and hospitalizations but large differences in costs, especially total and pharmacy costs.

Table 3 also reports the results from multiple multivariable regression analyses that assessed association of DMARD use 
with HCRU and costs after controlling for demographic and clinical characteristics. Use of DMARDs was associated with $14.5 \%$ fewer hospitalizations $(P<0.0001)$ and $18.0 \%$ fewer ED visits $(P<0.0001)$. Among patients using DMARDs, while total costs increased by $15.1 \%(P<0.0001)$, total costs, excluding DMARD treatment costs, decreased by $13.7 \%(P<0.0001)$.

Table 4 examines patient and provider characteristics that were associated with use of DMARDs among patients with RA. Women had higher odds (32.2\%) of use of DMARDs than men. Higher CIRAS (47.0\%) and RxRisk-V scores (26.7\%) and use of glucocorticoids (17.7\%) were associated with use of DMARDs $(P<0.0001)$. Among provider characteristics, visit to a rheumatologist (34.3\%) and solo practice (36.3\%) were associated with use of DMARDs. Use of certain classes of medications, such as NSAIDs (12.3\%), opioids (19.5\%), antidepressants (20.0\%), muscle relaxants (12.5\%), and anticonvulsants (15.5\%), reduced the chance of use of DMARDs.

Among patients with RA in 2014 and enrolled in 2013 and 2014, we identified patients newly diagnosed with RA (Figure 1). Only 29.4\% of these patients had been treated with DMARDs. The demographic and clinical characteristics of these newly diagnosed RA patients during the measurement year (results not shown) were similar to the overall population (Tables 1 and 2). Additionally, patient and provider characteristics associated with use of DMARDs among these patients were similar to the findings in the overall population with RA (results not shown).

\section{Discussion}

Although there are studies that have reported the use of DMARDs in the RA population, ${ }^{14,16,31-33}$ this study was predominantly focused on understanding patient and provider characteristics associated with DMARD use and its effect on HCRU and health care costs. Overall, in our study, we found three quarters of the patients with RA did have DMARD use in 2014 per HEDIS criteria. The national average 2014 DMARD treatment rate in MAPD plans was $76.7 \%$ for HMO plans and $80.5 \%$ for PPO plans, similar to what we observed in this study. Since 2014, there have been minimal changes to the national average DMARD use with DMARD treatment rate at $78.5 \%$ for PPO plans and $77.5 \%$ for HMO plans. ${ }^{19}$ A systematic review of studies identifying use of DMARDs using administrative claims data reported the use to be 30\%-63\%, ${ }^{31}$ which is lower than our findings; however, it should be noted these are results of studies published before 2013.

Studies have noted that use of DMARDs have been increasing over time..$^{14,16,17}$ In a study evaluating DMARD use between 2008 and 2014 among patients with RA by metropolitan statistical area (MSA), $64.5 \%$ patients in an average MSA were treated with DMARDs, which is lower than the DMARD use in the current study. ${ }^{34}$ In the current study, less than one third of patients newly diagnosed with RA in 2014 received

\begin{tabular}{|c|c|c|c|}
\hline \multirow{2}{*}{$\begin{array}{l}\text { TABLE } 1 \\
\text { Measure }\end{array}$} & \multicolumn{3}{|c|}{$\begin{array}{l}\text { emographic Characteristics of Patients } \\
\text { ith RA by DMARD Use During the } \\
\text { leasurement Year (2014) }\end{array}$} \\
\hline & DMARD Use & No DMARD Use & $P$ Value \\
\hline $\mathrm{n}(\%)$ & $25,483(75.2)$ & $8,397(24.8)$ & \\
\hline Age in years, mean (SD) & $67.0(10.7)$ & $68.9(10.7)$ & $<0.0001^{\mathrm{a}}$ \\
\hline \multicolumn{3}{|l|}{ Gender, n (\%) } & $<0.0001^{b}$ \\
\hline Male & $6,142(24.1)$ & $2,434(29.0)$ & \\
\hline Female & $19,339(75.9)$ & $5,963(71.0)$ & \\
\hline \multicolumn{3}{|l|}{ Race/ethnicity, n (\%) } & $<0.0001^{b}$ \\
\hline White & $17,918(70.3)$ & $6,477(77.1)$ & \\
\hline Black & $3,601 \quad(14.1)$ & $1,056(12.6)$ & \\
\hline Other/unknown & $1,205 \quad(4.7)$ & $383 \quad(4.6)$ & \\
\hline Missing & $2,759(10.8)$ & $481 \quad(5.7)$ & \\
\hline \multicolumn{3}{|l|}{ Geographic region, n (\%) } & $0.3955^{b}$ \\
\hline Northeast & $491 \quad(1.9)$ & $164 \quad(2.0)$ & \\
\hline Midwest & 4,993 (19.6) & $1,575(18.8)$ & \\
\hline South & $17,473(68.6)$ & $5,811(69.2)$ & \\
\hline West & $2,515 \quad(9.9)$ & $847(10.1)$ & \\
\hline Missing & 0.00 & $11(0.04)$ & \\
\hline \multicolumn{3}{|l|}{ Urban vs. rural, n (\%) } & $<0.0001^{b}$ \\
\hline Urban & $16,075(63.1)$ & $5,019(59.8)$ & \\
\hline Suburban & $6,444(25.3)$ & $2,232(26.6)$ & \\
\hline Rural & $2,733(10.7)$ & $1,070(12.7)$ & \\
\hline Missing & $231 \quad(0.9)$ & $76 \quad(0.9)$ & \\
\hline \multicolumn{3}{|l|}{ Insurance type, n (\%) } & $<0.0001^{b}$ \\
\hline MAPD plan & $22,724(89.2)$ & $7,916(94.3)$ & \\
\hline Commercial & $2,759(10.8)$ & $481 \quad(5.7)$ & \\
\hline
\end{tabular}

DMARDs during the same year. In contrast, higher proportions of patients newly diagnosed with RA with DMARD use (39\%$78 \%$ ) are reported in the literature..$^{15,17,31}$ These studies used longer follow-up periods, which might have contributed to the higher rate of the DMARD use reported.

Several studies report higher use of DMARDs among patients with RA under the care of a rheumatologist supporting the current study results. ${ }^{14,17,31-33}$ Patients under the care of the rheumatologist were reported twice as likely to be treated with DMARDs, ${ }^{17,33}$ which is similar to the finding in this study.

Among those with RA, patients with DMARD use were only slightly different in demographic characteristics from patients with no DMARD use. We found a greater proportion of patients with RA and with DMARD use underwent biomarker tests (C-reactive protein, erythrocyte sedimentation rate); had more concomitant medications (higher RxRisk-V score); and had more severe RA (higher CIRAS score) compared with those with no DMARD use. These findings were further supported by the regression analyses wherein higher RxRisk-V and CIRAS scores were associated 


\begin{tabular}{|c|c|c|c|c|c|c|c|}
\hline & $\begin{array}{l}\text { der and } \\
\text { (2014) }\end{array}$ & (1) પાI & $\theta$ & . & & & \\
\hline Measure & DMARD Use & No DMARD Use & $P$ Value & Measure & DMARD Use & No DMARD Use & $P$ Value \\
\hline $\mathrm{n}(\%)$ & $25,483 \quad(75.2)$ & $8,397(24.8)$ & & \multicolumn{4}{|c|}{ Prespecified medication use, n (\%) } \\
\hline \multicolumn{4}{|c|}{ Receipt of biomarker tests, $\mathrm{n}(\%)$} & Antidepressants & $9,793 \quad(38.4)$ & $2,796 \quad(33.3)$ & $<0.0001^{\mathrm{a}}$ \\
\hline Rheumatoid factor & $6,250 \quad(24.5)$ & $2,031 \quad(24.2)$ & $0.5308^{a}$ & Muscle relaxants & $4,429 \quad(17.4)$ & $1,316(15.7)$ & $0.0003^{\mathrm{a}}$ \\
\hline Cyclic citrullinated & 4,988 (19.6) & $1,265 \quad(15.1)$ & $<0.0001^{\mathrm{a}}$ & Anticonvulsants & $6,292 \quad(24.7)$ & $1,838 \quad(21.9)$ & $<0.0001^{\mathrm{a}}$ \\
\hline peptide antibody & & & & \multicolumn{4}{|l|}{ DMARD use, n (\%) } \\
\hline C-reactive protein & $15,836 \quad(62.1)$ & $2,925(34.8)$ & $<0.0001^{\mathrm{a}}$ & csDMARDs & $23,892(93.8)$ & $0 \quad(0.0)$ & \\
\hline Erythrocyte & $17,756(69.7)$ & $3,647 \quad(43.4)$ & $<0.0001^{\mathrm{a}}$ & JAKi & $353 \quad(1.4)$ & $0 \quad(0.0)$ & \\
\hline sedil & & & & TNFi & $4,331 \quad(17.0)$ & $0 \quad(0.0)$ & \\
\hline \multicolumn{4}{|l|}{ DCCI } & Non-TNFi & $1,542 \quad(6.1)$ & $0 \quad(0.0)$ & \\
\hline Median (IQR) & $2.0 \quad(2.0)$ & $2.0 \quad(2.0)$ & & \multicolumn{4}{|l|}{ Provider related } \\
\hline \multicolumn{4}{|l|}{ RxRisk-V score } & \multicolumn{3}{|c|}{ Principal provider specialty (categories are data driven), n (\%) } & $<0.0001^{\mathrm{a}}$ \\
\hline Mean (SD) & $7.4 \quad(3.1)$ & $6.4 \quad(3.4)$ & $<0.0001^{b}$ & \multicolumn{2}{|c|}{\begin{tabular}{l|rr} 
Primary care & $13,187 \quad(51.7)$ \\
\end{tabular}} & $5,003(59.6)$ & \\
\hline Median (IQR) & $7.0 \quad(5.0)$ & $6.0 \quad(5.0)$ & & Rheumatologist & & $1,111(13.2)$ & \\
\hline \multicolumn{3}{|l|}{ CIRAS score } & $<0.0001^{b}$ & \multirow{2}{*}{$\begin{array}{l}\text { Pain/orthopedic related } \\
\text { Other }\end{array}$} & \multirow{2}{*}{$\begin{array}{rr}472 & (1.9) \\
1,605 & (6.3) \\
\end{array}$} & $421 \quad(5.0)$ & \\
\hline Mean (SD) & $4.5 \quad(1.4)$ & $3.8 \quad(1.5)$ & & & & $565 \quad(6.7)$ & \\
\hline Median (IQR) & $4.3 \quad(1.9)$ & $3.6 \quad(2.2)$ & & Unknown $^{\mathrm{d}}$ & $3,233(12.7)$ & $1,297(15.4)$ & \\
\hline \multicolumn{3}{|c|}{ Timing of first qualifying RA diagnosis, days (\%)c } & $<0.0001^{b}$ & \multicolumn{3}{|c|}{ Type of practice of principal provider, $\mathrm{n}(\%)$} & $0.1440^{\mathrm{a}}$ \\
\hline Mean (SD) & $51.4(53.8)$ & $75.6(71.2)$ & & Group & $17,923(70.3)$ & $5,842(69.6)$ & \\
\hline Median (IQR) & $34.0(55.0)$ & $54.0(90.0)$ & & Solo & $5,527(21.7)$ & $1,723(20.5)$ & \\
\hline \multicolumn{3}{|c|}{ Timing between first and second qualifying RA diagnosis, days (\%) } & $<0.0001^{b}$ & Facility & $1,721 \quad(6.8)$ & $594 \quad(7.1)$ & \\
\hline Mean (SD) & $49.5(49.0)$ & $64.9(61.6)$ & & Missing & $312 \quad(1.2)$ & $238 \quad(2.8)$ & \\
\hline Median (IQR) & $34.0(64.0)$ & $44.0(79.0)$ & & \multicolumn{3}{|c|}{ Principal provider type, $\mathrm{n}(\%)$} & $<0.0001^{\mathrm{a}}$ \\
\hline \multicolumn{4}{|l|}{ Treatment related } & Medical doctor & $16,005(62.8)$ & $4,891(58.2)$ & \\
\hline \multicolumn{4}{|c|}{ Prespecified medication use, $\mathrm{n}(\%)$} & Not medical doctor & $1,545 \quad(6.1)$ & $888(10.6)$ & \\
\hline \multirow{2}{*}{$\begin{array}{l}\text { Nonsteroidal anti- } \\
\text { inflammatory drugs }\end{array}$} & $9,578 \quad(37.6)$ & $2,620 \quad(31.2)$ & $<0.0001^{\mathrm{a}}$ & Unknown $^{\mathrm{d}}$ & $7,281 \quad(28.6)$ & $2,618 \quad(31.2)$ & \\
\hline & & & & \multicolumn{3}{|c|}{ Unique providers managing the care of RA patient, $\mathrm{n}(\%)$} & $<0.0001^{\mathrm{b}}$ \\
\hline Glucocorticoids & $15,250 \quad(59.8)$ & $3,066 \quad(36.5)$ & $<0.0001^{\mathrm{a}}$ & Mean (SD) & $5.7 \quad(3.5)$ & $5.4 \quad(3.5)$ & \\
\hline Opioids & $16,100(63.2)$ & $4,664 \quad(55.5)$ & $0.0060^{\mathrm{a}}$ & Median (IQR) & $5.0 \quad(4.0)$ & $5.0 \quad(4.0)$ & \\
\hline \multicolumn{8}{|c|}{$\begin{array}{l}\text { aChi-square tests. } \\
{ }^{b} \text { T-test. } \\
\text { 'Timing of first qualifying RA diagnosis: time of first claim with RA diagnosis. } \\
\text { dUnknown provider reflects inadequate description of providers. } \\
\text { CIRAS= claims-based index for rheumatoid arthritis severity; } \operatorname{cs} D M A R D=\text { conventional synthetic disease-modifying antirheumatic drug; DCCI=Deyo-Charlson } \\
\text { Comorbidity Index; DMARD = disease-modifying antirheumatic drug; IQR = interquartile range; JAKi=Janus kinase inhibitors; RA=rheumatoid arthritis; } S D=\text { standard } \\
\text { deviation; TNFi=tumor necrosis factor inhibitor. }\end{array}$} \\
\hline
\end{tabular}

with DMARD use. We also have observed higher DCCI was associated with lower odds of DMARD use. Although DCCI is measured using diagnosis codes, RxRisk-V score is based on medication use. The difference in the association may indicate that comorbidities were better identified by the prescription drug use. It may also indicate that patients with higher comorbidity index were more reluctant to receive the DMARD treatment. It is also observed in the shorter time between visits with claims for RA for patients with DMARD use compared with those with no DMARD use.

Similar to the findings by Solomon et al. (2014), we observed an association of glucocorticoid use with DMARD use. ${ }^{32}$ In contrast, the use of certain classes of medications (NSAIDs, opioids, antidepressants, muscle relaxants, and anticonvulsants) contributed to a lower chance of use of DMARDs. This finding indicates that these medications might be used for symptomatic management of RA, especially NSAIDs and opioids, in place of DMARD treatment.

We could not identify any published studies that evaluated the overall effect of the DMARD use (csDMARDs and bDMARDs) on HCRU and health care costs. In the current study, there were minimal differences in HCRU in the descriptive analyses of patients comparing patients with and without DMARD use. When controlling for demographic and clinical characteristics, we found the use of DMARDs was associated with fewer hospitalizations, fewer ED visits, and lower total health care costs excluding DMARDs compared with those with no DMARD use. Fewer hospitalizations and ED visits 
TABLE 3 HCRU and Costs Among RA Patients with and Without DMARD Use During the Measurement Year (2014) and Follow-Up Year (2015) Enrolled in MAPD Plans: Descriptive and Regression Analyses

\begin{tabular}{|c|c|c|c|c|c|c|c|}
\hline \multicolumn{4}{|l|}{ Descriptive Analyses $^{\mathrm{a}}$} & \multicolumn{4}{|l|}{ Descriptive Analyses ${ }^{a}$} \\
\hline & \multirow{2}{*}{$\begin{array}{l}\text { DMARD } \\
\text { Use }\end{array}$} & \multirow{2}{*}{$\begin{array}{l}\text { No DMARD } \\
\text { Use }\end{array}$} & \multirow[b]{2}{*}{$P$ Value } & \multicolumn{4}{|l|}{ All-cause pharmacy costs, $\$$} \\
\hline & & & & \multirow{2}{*}{ Measurement year, mean (SD) } & \multirow{2}{*}{$\begin{array}{c}6,703.7 \\
(12,935.7) \\
\end{array}$} & \multirow{2}{*}{$\begin{array}{c}3,400.8 \\
(20,294.7) \\
\end{array}$} & \multirow{3}{*}{$<0.0001$} \\
\hline $\mathrm{n}(\%)$ & $19,721(75.5)$ & $6,382(24.5)$ & & & & & \\
\hline \multicolumn{4}{|l|}{ All-cause hospitalizations, $\mathrm{n}$} & Median & $2,375.8$ & $1,092.0$ & \\
\hline Measurement year, mean (SD) & $0.3(0.7)$ & $0.4(0.8)$ & \multirow{2}{*}{$<0.0001$} & \multirow{2}{*}{ Follow-up year, mean (SD) } & \multirow{2}{*}{$\begin{array}{c}7,713.0 \\
(17,972.2) \\
\end{array}$} & \multirow{2}{*}{$\begin{array}{c}4,217.5 \\
(21,389.5) \\
\end{array}$} & \multirow{3}{*}{$<0.0001$} \\
\hline Median & 0.0 & 0.0 & & & & & \\
\hline Follow-up year, mean (SD) & $0.3(0.8)$ & $0.4(0.9)$ & \multirow{2}{*}{$<0.0001$} & Median & $2,607.0$ & $1,183.2$ & \\
\hline Median & 0.0 & 0.0 & & \multicolumn{4}{|c|}{ All-cause costs (excluding DMARDs), \$ } \\
\hline \multicolumn{4}{|l|}{ All-cause outpatient visits, $\mathrm{n}$} & Measurement year, mean (SD) & $13,255.24$ & $15,596.10$ & \multirow{3}{*}{0.450} \\
\hline Measurement year, mean (SD) & $21.5(15.4)$ & $19.9(16.1)$ & \multirow{2}{*}{$<0.0001$} & Median & $\frac{(20,990.62)}{6781.74}$ & $\frac{(30,}{66}$ & \\
\hline Median & 18.0 & 16.0 & & Eollowt & 1482574 & $\frac{1600.91}{0.0170}$ & \\
\hline Follow-up year, mean (SD) & $21.6(16.1)$ & $19.8(18.3)$ & \multirow{2}{*}{$<0.0001$} & Follow-up year, mean (SD) & $(26,372.93)$ & $(31,523.63)$ & \multirow{2}{*}{0.0001} \\
\hline Median & 18.0 & 16.0 & & Median & $7,225.36$ & $6,635.50$ & \\
\hline \multicolumn{4}{|l|}{ All-cause ED visits, $\mathrm{n}$} & \multicolumn{4}{|l|}{ All-cause total costs, $\$$} \\
\hline Measurement year, mean (SD) & $0.9(1.9)$ & $1.1(2.3)$ & \multirow{2}{*}{$<0.0001$} & Measurement year, mean (SD) & $18,085.4$ & $15,611.1$ & \multirow{3}{*}{$<0.0001$} \\
\hline Median & 0.0 & 0.0 & & & $(23,789.2)$ & $(30,215.0)$ & \\
\hline Follow-up year, mean (SD) & $1.0(2.2)$ & $1.2(2.7)$ & \multirow{2}{*}{$<0.0001$} & Median & $9,079.4$ & $6,686.7$ & \\
\hline Median & 0.0 & 0.0 & & Follow-up year, mean (SD) & $19,920.1$ & $16,544.6$ & $<0,0001$ \\
\hline \multicolumn{4}{|c|}{ All-cause outpatient visits to a rheumatologist, $\mathrm{n}$} & & $(29,138.2)$ & $(31,781.7)$ & $<0.0001$ \\
\hline Measurement year, mean (SD) & $1.0(2.3)$ & $0.4(1.3)$ & $<0 \cap 0 \Omega 1$ & Median & $9,284.2$ & $6,773.8$ & \\
\hline Median & 0.0 & 0.0 & $<0.0001$ & Regression Analyses $^{\text {b }}$ & & & \\
\hline Follow-up year, mean (SD) & $1.0(2.3)$ & $0.4(1.3)$ & $<0.0001$ & & & $95 \%$ CI of & \\
\hline Median & 0.0 & 0.0 & & & $\exp ($ Beta & $\exp ($ Beta & \\
\hline All-cause medical costs, $\$$ & & & & & estimate) & estimate) & $P$ Value \\
\hline Measurement year, mean (SD) & $11,382.7$ & $12,210.3$ & & Hospitalizations & 0.855 & $0.807-0.907$ & $<0.0001$ \\
\hline & $(18,889.1)$ & $(20,956.6)$ & 0.005 & $\underline{\text { ED visits }}$ & 0.820 & $0.796-0.845$ & $<0.0001$ \\
\hline Median & $4,577.8$ & $4,404.6$ & & Outpatient visits & 1.038 & $1.301-1.046$ & $<0.0001$ \\
\hline Follow-up year, mean (SD) & $12,207.2$ & $12,327.1$ & & Total health care costs & 1.151 & $1.117-1.187$ & $<0.0001$ \\
\hline Median & $\frac{(21,336.6)}{46788}$ & $\frac{(22,419.8)}{42253}$ & $<0.0001$ & Total health care costs & 0.863 & $0.838-0.889$ & $<0.0001$ \\
\hline${ }^{2}$ Kruskal-Wallis tes & th care re & ise and $\cos$ & & osts were evaluated for indi & & & \\
\hline $\begin{array}{l}\text { bor regression analyses, reference } \\
\text { distribution for cost variables. } \\
C I=\text { confidence interval; DMARD }\end{array}$ & DMAR & with log & $d F$ & $\begin{array}{l}\text { ribution was used for utiliz } \\
y \text { department; GLM = gen }\end{array}$ & sanc & log-lin & $m m a$ \\
\hline
\end{tabular}

might have contributed to the lower medical costs among DMARD users. As a result, while pharmacy costs due to DMARDs were higher, the reduced medical and other pharmacy costs contributed to the lower total health care cost.

Previous studies reported various reasons for patients not switching their DMARD therapy. ${ }^{35,36}$ The most common reasons reported were risk of side effects, inconvenience of additional tests, insurance coverage, fear of intravenous administration or injection, and cost of a new treatment. Many of these reasons, however, are not relevant to csDMARDs as these treatments are generic, low cost and available for oral administration. The majority of patients in this study were previously diagnosed with RA, which might indicate that those without DMARD use during the study period either did not start their DMARD, which is usually first-line csDMARD, or discontinued their previous DMARD therapy. Future research should focus on understanding the reasons for patients to not initiate or to discontinue their DMARD therapy.

\section{Limitations}

Typical to retrospective, claims-based research, this study might have potential errors in coding, omissions in claims data, and unmeasured factors such as psychosocial variables. Additionally, lack of medical records might contribute to unmeasured confounding associated with treatment choices and reasons behind physicians' decisions. Free samples given to a patient upon the diagnosis or manufacturer patient assistance/access programs might have affected the rates of DMARD use among patients newly diagnosed with RA. Although the study data were drawn from a large national health plan with 


\begin{tabular}{|c|c|c|c|c|c|c|c|c|c|}
\hline \multirow[b]{2}{*}{ Age } & \multirow{2}{*}{$\begin{array}{l}\begin{array}{l}\text { Odds } \\
\text { Ratio }\end{array} \\
1.016 \\
\end{array}$} & \multicolumn{2}{|c|}{ 95\% Wald CL } & \multirow{2}{*}{$\begin{array}{l}P \text { Value } \\
<0.0001\end{array}$} & & $\begin{array}{l}\text { Odds } \\
\text { Ratio }\end{array}$ & \multicolumn{2}{|c|}{ 95\% Wald CL } & \multirow[t]{2}{*}{$P$ Value } \\
\hline & & 1.012 & 1.021 & & \multicolumn{4}{|l|}{ Prespecified medication use } & \\
\hline CIRAS score & 1.470 & 1.425 & 1.516 & $<0.0001$ & Muscle relaxants & 0.766 & 0.698 & 0.841 & $<0.0001$ \\
\hline Gender, female & 1.322 & 1.225 & 1.427 & $<0.0001$ & Anticonvulsants & 0.713 & 0.655 & 0.777 & $<0.0001$ \\
\hline \multicolumn{5}{|l|}{ Race (reference: white) } & \multicolumn{5}{|c|}{ Health care resource utilization } \\
\hline Black & 1.004 & 0.911 & 1.106 & 0.4259 & Durable medical & 1.161 & 0.926 & 1.456 & 0.1953 \\
\hline $\begin{array}{l}\text { Other/unknown/ } \\
\text { missing }\end{array}$ & 0.917 & 0.787 & 1.067 & 0.2588 & $\begin{array}{l}\text { equipment use } \\
\text { Use of SNF }\end{array}$ & 0.721 & 0.512 & 1.016 & 0.0617 \\
\hline \multicolumn{5}{|l|}{ Region (reference: South) } & All-cause hospitalization & 1.011 & 0.937 & 1.091 & 0.7785 \\
\hline Northeast & 1.259 & 0.756 & 2.096 & 0.4463 & $\begin{array}{l}\text { LOS for all-cause } \\
\text { hospitalizations }\end{array}$ & 0.990 & 0.982 & 0.999 & 0.0255 \\
\hline Midwest & 1.242 & 0.99 & 1.558 & 0.1969 & All-cause outpatient visits & 0.996 & 0.993 & 0.998 & 0.001 \\
\hline West & 0.881 & 0.737 & 1.054 & 0.0269 & All-cause ED visits & 0.907 & 0.889 & 0.924 & $<0.0001$ \\
\hline \multicolumn{5}{|c|}{ Population density (reference: urban) } & Total medical cost & 0.900 & 0.863 & 0.939 & $<0.0001$ \\
\hline Suburban & 0.903 & 0.835 & 0.976 & 0.0487 & \multicolumn{5}{|l|}{ Provider characteristics } \\
\hline Rural/missing & 0.961 & 0.865 & 1.067 & 0.8329 & \multirow{2}{*}{$\begin{array}{l}\text { At least } 1 \text { visit to the } \\
\text { rheumatologist }\end{array}$} & \multirow[t]{2}{*}{1.803} & \multirow[t]{2}{*}{1.634} & \multirow[t]{2}{*}{1.988} & \multirow[t]{2}{*}{$<0.0001$} \\
\hline DCCI score & 0.892 & 0.874 & 0.910 & $<0.0001$ & & & & & \\
\hline RxRisk-V Score & 1.267 & 1.246 & 1.287 & $<0.0001$ & \multicolumn{5}{|c|}{ Provider practice (reference: group) } \\
\hline $\begin{array}{l}\text { Timing of first qualifying } \\
\text { RA diagnosis }\end{array}$ & 0.993 & 0.992 & 0.993 & $<0.0001$ & $\begin{array}{l}\text { Facility } \\
\text { Solo } \\
\end{array}$ & $\begin{array}{l}1.318 \\
1.827 \\
\end{array}$ & $\begin{array}{l}1.135 \\
1.296 \\
\end{array}$ & $\begin{array}{l}1.531 \\
2.576 \\
\end{array}$ & $\begin{array}{l}0.817 \\
0.008 \\
\end{array}$ \\
\hline \multirow{2}{*}{$\begin{array}{l}\text { Timing between first and } \\
\text { second qualifying RA } \\
\text { diagnosis }\end{array}$} & \multirow[t]{2}{*}{0.995} & \multirow[t]{2}{*}{0.994} & \multirow[t]{2}{*}{0.995} & \multirow[t]{2}{*}{$<0.0001$} & \multicolumn{5}{|c|}{ Provider region (reference: Northeast) } \\
\hline & & & & & $\begin{array}{l}\text { Missing } \\
\text { Midwest }\end{array}$ & $\begin{array}{l}1.247 \\
1.077\end{array}$ & $\begin{array}{l}0.707 \\
0.613\end{array}$ & $\begin{array}{l}2.200 \\
1.892\end{array}$ & $\begin{array}{l}0.2143 \\
0.9223\end{array}$ \\
\hline \multicolumn{5}{|l|}{ Prespecified medication use } & South & 1.019 & 0.603 & 1.092 & 0.3539 \\
\hline NSAIDs & 0.769 & 0.716 & 0.827 & $<0.0001$ & West & 1.114 & 0.648 & 1.916 & 0.7852 \\
\hline Glucocorticoids & 1.385 & 1.29 & 1.486 & $<0.0001$ & \multicolumn{5}{|c|}{ Provider credentials (reference: non-MD) } \\
\hline Opioids & 0.647 & 0.597 & 0.702 & $<0.0001$ & MD & 1.774 & 1.579 & 1.993 & 0.1226 \\
\hline Antidepressants & 0.641 & 0.592 & 0.694 & $<0.0001$ & Missing & 2.368 & 1.665 & 3.368 & 0.0009 \\
\hline
\end{tabular}

persons enrolled throughout the United States, the results may not be generalizable to the overall U.S. population or to specific subpopulations in certain geographic regions. Moreover, the results may not be generalizable to all Medicare beneficiaries due to differences in benefit structures of MAPD vs. nonMAPD health plans.

The study used HEDIS criteria to assess DMARD use among patients diagnosed with RA. This measurement includes the assessment during a specific calendar year and therefore might underestimate the rate of DMARD use among newly diagnosed patients who were diagnosed with RA at the end of the calendar year.

Additionally, the provider selection algorithm might not accurately capture the treating physician for the patients in the study as the principal provider was assigned based on the first observed rheumatologist visit or RA diagnosis. The descriptive results for hospitalizations and ED visits should be interpreted with caution because the median values are zero, indicating that at least $50 \%$ of the patients did not have any hospitalization and/or ED visit. Furthermore, factors such as adherence to DMARD medication and other clinical factors, which could provide additional insight for the effect of DMARD use on HCRU and costs were out of scope for this study. Due to the large patient sample size in the study, many outcomes evaluated were found to be statistically significant; however, statistically significant findings are not always clinically meaningful.

\section{Conclusions}

Overall, three quarters of patients with RA, and less than one third of patients newly diagnosed with RA, used DMARDs in 2014. We found significant differences in demographic and clinical characteristics among patients with and without DMARD use. These differences should inform treatment decisions regarding DMARD use as deemed necessary by the provider among patients with RA. Future work should investigate the reasons for lack of DMARD treatment. 


\section{Authors}

NATALIE N. BOYTSOV, PhD; KIM SAVERNO, PhD, RPh; XIANG ZHANG, PhD; and CAROL L. GAICH, PharmD, RPh, Eli Lilly, Indianapolis, Indiana. RITUPURNA BHATTACHARYA, PhD, and RADHIKA NAIR, PhD, Humana Healthcare Research, Louisville, Kentucky. LAURIN DIXON, PharmD, and PAUL L. ABBOTT, MBA, Humana, Louisville, Kentucky.

AUTHOR CORRESPONDENCE: Natalie N. Boytsov, PhD, Eli Lilly, Lilly Corporate Center, Indianapolis, IN 46285. Tel.: 317.433.5924;

E-mail: boytsov_natalie_n@lilly.com.

\section{DISCLOSURES}

This study was supported by funding from Eli Lilly to Humana as a collaborative research project involving employees of both companies. Boytsov, Saverno, Zhang, and Gaich are employees of Eli Lilly. Nair, Bhattacharya, Abbott, and Dixon are employees of Humana, which received funding from Eli Lilly to complete this research.

\section{ACKNOWLEDGMENTS}

The authors acknowledge Mary Costantino, $\mathrm{PhD}$, for her editorial support in developing the manuscript.

\section{REFERENCES}

1. Anderson R. Rheumatoid arthritis: clinical and laboratory features. In: Klippel JH, ed. Primer on the Rheumatic Diseases. 12th ed. Atlanta, GA: Arthritis Foundation; 2001:218

2. Hunter TM, Boytsov NN, Zhang X, Schroeder K, Michaud K, Araujo AB Prevalence of rheumatoid arthritis in the United States adult population in healthcare claims databases, 2004-2014. Rheumatol Int. 2017;37(9):1551-57. 3. Helmick CG, Felson DT, Lawrence RC, et al; National Arthritis Data Workgroup.. Estimates of the prevalence of arthritis and other rheumatic conditions in the United States. Part I. Arthritis Rheum. 2008;58(1):15-25.

4. Kiely PDW, Nikiphorou E. Management of rheumatoid arthritis. Medicine. 2018;46(4):216-21

5. Sarzi-Puttini P, Salaffi F, Di Franco M, et al. Pain in rheumatoid arthritis: a critical review. Reumatismo. 2014;66(1):18-27.

6. Wolfe F, Michaud K. Assessment of pain in rheumatoid arthritis: minimal clinically significant difference, predictors, and the effect of anti-tumor necrosis factor therapy. J Rheumatol. 2007;34(8):1674-83.

7. Steiman AJ, Pope JE, Thiessen-Philbrook H, et al. Non-biologic disease-modifying antirheumatic drugs (DMARDs) improve pain in inflammatory arthritis (IA): a systematic literature review of randomized controlled trials. Rheumatol Int 2013;33(5):1105-20.

8. Singh JA, Saag KG, Bridges SL Jr, et al. 2015 American College of Rheumatology Guideline for the Treatment of Rheumatoid Arthritis. Arthritis Rheumatol. 2016;68(1):1-26.

9. Smolen JS, Landewe R, Bijlsma J, et al. EULAR recommendations for the management of rheumatoid arthritis with synthetic and biological disease-modifying antirheumatic drugs: 2016 update. Ann Rheum Dis. 2017;76(6):960-77.

10. van der Linden MP, le Cessie S, Raza K, et al. Long-term impact of delay in assessment of patients with early arthritis. Arthritis Rheum. 2010;62(12):3537-46 11. Nell VPK, Machold KP, Eberl G, Stamm TA, Uffmann M, Smolen JS. Benefit of very early referral and very early therapy with disease-modifying anti-rheumatic drugs in patients with early rheumatoid arthritis. Rheumatology. 2004;43(7):906-14 12. Bonafede MM, Fox KM, Johnson BH, Watson C, Gandra SR. Factors associated with the initiation of disease-modifying antirheumatic drugs in newly diagnosed rheumatoid arthritis: a retrospective claims database study. Clin Ther. 2012;34(2):457-67.

13. Khanna R, Smith MJ. Utilization and costs of medical services and prescription medications for rheumatoid arthritis among recipients covered by a state Medicaid program: a retrospective, cross-sectional, descriptive, database analysis Clin Ther. 2007;29(11):2456-67

14. Schmajuk G, Schneeweiss S, Katz JN, et al. Treatment of older adult patients diagnosed with rheumatoid arthritis: improved but not optimal. Arthritis Rheum. 2007;57(6):928-34.
15. Crane MM, Juneja M, Allen J, et al. Epidemiology and treatment of new-onset and established rheumatoidaArthritis in an insured U.S. population. Arthritis Care Res. 2015;67(12):1646-55

16. Schmajuk G, Trivedi AN, Solomon DH, et al. Receipt of disease-modifying antirheumatic drugs among patients with rheumatoid arthritis in Medicare managed care plans. JAMA. 2011;305(5):480-86.

17. Widdifield J, Bernatsky S, Paterson JM, et al. Quality care in seniors with new-onset rheumatoid arthritis: a Canadian perspective. Arthritis Care Res. 2011;63(1):53-57.

18. Kern DM, Chang L, Sonawane K, et al. Treatment patterns of newly diagnosed rheumatoid arthritis patients from a commercially insured population. Rheumatol Ther. 2018;5(2):355-69.

19. National Committee for Quality Assurance. Healthcare Effectiveness Data and Information Set. 2019. Available at: http://www.ncqa.org/hedis-quality-measurement. Accessed June 14, 2019

20. National Committee for Quality Assurance, Healthcare Effectiveness Data and Information Set. Disease-modifying anti-rheumatic drug therapy for rheumatoid arthritis. 2019. Available at: https://www.ncqa.org/hedis/measures/diseasemodifying-anti-rheumatic-drug-therapy-for-rheumatoid-arthritis/. Accesed June $14,2019$.

21. Centers for Medicare \& Medicaid Services. 2017 star ratings. October 12, 2016. Available at: https://www.cms.gov/newsroom/fact-sheets/2017-star-ratings. Accessed June 12, 2019.

22. Congressional Budget Office Working Paper Series. An analysis of privatesector prices for physicians' services. Working Paper 2018-01. January 2018. Available at: https://www.cbo.gov/system/files/115th-congress-2017-2018/ workingpaper/53441-workingpaper.pdf. Accessed

June 12, 2019.

23. Maeda JLK, Nelson L. How do the hospital prices paid by Medicare Advantage plans and commercial plans compare with Medicare fee-for-service prices? Inquiry. 2018;55:46958018779654.

24. Archer D, Mamor, T. Medicare and commercial health insurance: the fundamental difference. February 15, 2012. Available at: https://www.healthaffairs.org/ do/10.1377/hblog20120215.016980/full/. Accessed June 12,2019.

25. Deyo RA, Cherkin DC, Ciol MA. Adapting a clinical comorbidity index for use with ICD-9-CM administrative databases. J Clin Epidemiol. 1992;45(6):61319.

26. Quan H, Parsons GA, Ghali WA. Validity of information on comorbidity derived from ICD-9-CCM administrative data. Med Care. 2002;40(8):675-85.

27. Klabunde CN, Potosky AL, Legler JM, Warren JL. Development of a comorbidity index using physician claims data. J Clin Epidemiol. 2000;53(12):1258-67. 28. Sloan KL, Sales AE, Liu CF, et al. Construction and characteristics of the RxRisk-V: A VA-adapted pharmacy-based case-mix instrument. Med Care. 2003;41(6):761-74.

29. Ting G, Schneeweiss S, Scranton R, et al. Development of a health care utilisation data-based index for rheumatoid arthritis severity: a preliminary study Arthritis Res Ther. 2008;10(4):R95.

30. Deb P, Norton EC. Modeling health care expenditures and use. Annu Rev Public Health. 2018;39:489-505.

31. Schmajuk G, Solomon DH, Yazdany J. Patterns of disease-modifying antirheumatic drug use in rheumatoid arthritis patients after 2002: a systematic review. Arthritis Care Res. 2013;65(12):1927-35.

32. Solomon DH, Tonner C, Lu B, et al. Predictors of stopping and starting disease-modifying antirheumatic drugs for rheumatoid arthritis. Arthritis Care Res. 2014;66(8):1152-58.

33. Solomon DH, Yelin E, Katz JN, Lu B, Shaykevich T, Ayanian JZ. Treatment of rheumatoid arthritis in the Medicare Current Beneficiary Survey. Arthritis Res Ther. 2013;15(2):R43

34. Shafrin J, Ganguli A, Gonzalez YS, Shim JJ, Seabury SA. Geographic variation in the quality and cost of care for patients with rheumatoid arthritis. $J$ Manag Care Spec Pharm. 2016;22(12):1472-81. Available at: https://www.jmcp.org/ doi/10.18553/jmcp.2016.22.12.1472.

35. Wolfe F, Michaud K. Resistance of rheumatoid arthritis patients to changing therapy: discordance between disease activity and patients' treatment choices. Arthritis Rheum. 2007;56(7):2135-42

36. Kamal KM, Madhavan SS, Hornsby JA, Miller LA, Kavookjian J, Scott V. Use of tumor necrosis factor inhibitors in rheumatoid arthritis: a national survey of practicing United States rheumatologists. Joint Bone Spine. 2006;73(6):718-24. 